\title{
MANAGEMENT OF WOLF POPULATIONS IN THE CONDITIONS OF THE SOUTH PRIARALIE
}

\author{
Kidirbaeva Arzygul Yuldashevna ${ }^{1}$, Atashov Azhiniyaz Shaniyazovich ${ }^{2}$ \\ ${ }^{l}$ Doctor of Philosophy in Biological Sciences $(P h D)$ \\ ${ }^{2}$ Assistant, Department of Ecology of Soil Science \\ Karakalpak State University named after Berdakh \\ The Republic of Uzbekistan
}

Article DOI: https://doi.org/10.36713/epra9165

DOI No: 10.36713/epra9165

\begin{abstract}
ANNOTATION
The article discusses the basic principles of wolf management in the conditions of the Southern Priraralie. The management of wolf populations has its own characteristics. It is very important to know the spatial territorial structure of family-flocking areas. In addition, to have information about the number of indigenous areas occupied by him, the average fertility, mortality and the age structure of his populations.
\end{abstract}

KEYWORDS: regulation, management, poaching, fertility, radio tracking, convention.

Until recently, the question of managing wolf populations was not as acute as it is today. In the recent past, there was an established point of view about the harmfulness of the wolf and the measures to exterminate the predator. On the territory of the CIS countries, a struggle was waged everywhere to destroy wolf populations. As a result, the wolf was destroyed in most of its range, as well as in the United States, Mexico and Western Europe. Only since the 30s of the last century, scientists began to express an opinion about the revision of the ingrained views of the harmfulness of the wolf. In the second half of the 20th century, the attitude of man to nature and the preservation of biodiversity changed radically.

Numerous studies of the ecology of the wolf and its relationship with wild ungulates have confirmed the incorrectness of the scientific view on the program for the complete destruction of the predator. The American Society of Zoologists held the First Wolf Symposium in 1967. During this period, various organizations for the protection of wolves appeared in many countries of the world. At the initiative of WWF
(World Wildlife Fund ${ }^{1}$ ) and IUCN (International Union for Conservation of Nature $^{2}$ ), great interest was shown in the wolf, and this predator was included in the list of rare and endangered species of the IUCN Red List, not counting Russian subspecies. The group of specialists on the IUCN wolf was organized in 1973. In 1973, at the IUCN conference in Stockholm (Sweden), the International Manifesto for the Conservation of Wolves was adopted [1].

This manifesto includes the Declaration of Principles for the Conservation of the Wolf and the Recommended Guidelines for the Conservation of Wolves. The Manifesto was later revised by the IUCN Wolf Conservation Group on January 31, 1983, November 20, 1996, and February 23, 2000.

In 1973, the Convention on International Trade in Endangered Species includes the wolf in

\footnotetext{
${ }^{1}$ https://wwf.ru/

${ }^{2}$ https://wwf.ru
} 
Appendix II (potentially endangered species) ${ }^{3}$, with the exception of Bhutan, Pakistan, India and Nepal, where it is listed in Appendix I (endangered species).

The wolf is also included in Appendix I (strictly protected species) of the Berne Convention (Convention for the Conservation of European Wild Animals and Their Natural Habitats, 09/19/1979). Based on this convention, the wolf and its habitat receive full protection, although all contracting parties are responsible for compliance with this provision.

It is well known that the main goal of the Berne Convention is to maintain and restore, in coexistence with humans, a viable population of wolves as an integral part of ecosystems and landscapes throughout Europe. As noted in this Convention, restoration and conservation of wolves is an essential part of efforts to protect biodiversity in Europe and ensure the functionality of its ecosystems.

Considering the Berne Convention $\mathrm{Plan}^{4}$ in relation to the European part, we assume that the expansion of borders into the territory of Central Asia will provide an opportunity for a reasonable strategy in the management of wolf populations.

Wolves are a rather difficult object to study for traditional methods, their distribution was limited to remote areas, they were very mobile and their population density was very low. During this time, various methods have been developed to study the ecology of the wolf. In the early 1960s. one of the accounting methods was developed - radio tracking. This technology is considered especially valuable for wolf research. American scientist Kolenoskj (1967) was the first to conduct radio tracking of wolves in Ontario (province of Canada). Further Mech and Frenzel (Mech, Frenzel, 1971) combined this technology with tracking and observation from the air. After that, this method has become widely used in many countries around the world. Currently, this method is used by Kazakhstani scientists within the framework of the Altyn Dala project (a large-scale partnership program of national and international environmental organizations), which allowed them to clarify the number of wolves, their daily and seasonal movements, as well as their prey.

3

https://www.un.org/ru/documents/decl_conv/conven tions/cites.shtml

${ }^{4}$ https://www.coe.int/ru/web/impact-conventionhuman-rights/convention-on-the-conservation-ofeuropean-wildlife-and-natural-habitats\#/
Wolf management remains a highly controversial issue due to the complexity of the role of a predator in the economy and wildlife. Currently, the Republic of Uzbekistan is one of the countries where the reduction and regulation of the wolf population remains one of the urgent tasks in the conservation of biodiversity.

The management of wolf populations has its own characteristics. It is very important to know the spatial territorial structure of family-flocking areas. In addition, to have information about the number of indigenous areas occupied by him, the average fertility, mortality and the age structure of his populations. Knowledge of the boundaries of the indigenous areas of family flocks makes it possible to more efficiently and competently regulate their numbers.

Thus, in order to control the state of wolf resources in the South Aral Sea region and coordinate the efforts of inspectors and hunters, it is economically justified to create specialized operational wolf management services from game managers and gamekeepers under the controlling bodies. With the sparing "regulation" of the wolf population and the restriction of legal hunting for ungulates, it eliminates the inter-flock competition of the wolf, and the most favorable conditions for its reproduction are created.

When solving the problems of managing wolf populations, it is necessary to carry out an integrated approach, taking into account the ecologicalgeographical, socio-economic, moral and organizational aspects. Taking into account environmental aspects, when managing wolf populations, it is necessary to take into account the regulation of wolf numbers to an ecologically sound minimum limit at which viable populations will be preserved, and the assessment of damage from it to the economy will be minimal.

The only alternative approach to controlling a wolf is differentiated. It includes the regionalgeographical allocation of territories in which the wolf's range should be reduced due to the obvious damage to livestock and forestry. This approach will help maintain the size and structure. Wolf populations at a specific level for a specific area. According to Bibikov D.I. (1985), there are 4 types of wolf population regulation regimes:

1. Strict regulation includes up to the reduction of the area in regions with a high population density and intensive use of natural resources;

2. Moderate regulation and maintenance of an average density at the level of no more than two animals per $1,000 \mathrm{~km} 2$ in regions with a low population density and extensive nature management; 
3. The status of a game animal - in the area of distribution of wild ungulates;

4. Conservation - reserves and other protected areas.

The results of the research show that in the conditions of the Southern Aral Sea region, given the ecological and economic importance of the wolf, it is recommended to apply the category of "moderate regulation" in some places, and in most cases the category "protection". In these cases, a differentiated approach to the regulation of the wolf population is necessary from an ecological point of view $[2,3]$.

In our opinion, the presence of wolves may be incompatible with intensive human economic activities, therefore the best possible integration of human activities with the prudent protection of biological diversity should be planned. Since the regulation of their presence on the territory of a particular state cannot be entrusted to the individual reaction of shepherds who have suffered great damage or, even more so, poachers, the Management Plan should establish a number of goals, objectives, criteria and methods on the basis of which the presence will be corrected. of this kind. Without limiting the objectives of protecting viable wolf populations that are not threatened by the most likely risk factors, an initial understanding of the management of wolf populations by zone is needed. This will lead to the complete protection of the wolf only in a certain part of the territory, and thus, can provoke conflicts with farmers and shepherds in the zones most susceptible to attacks. This, in turn, will require the application of a number of measures, both preventive and remedial, including the removal of several individual individuals on a local scale $[3,4]$.

The feasibility of such an approach should be assessed at the environmental, social, administrative, environmental and ethical levels. From an ecological point of view, it seems possible and expedient: the high annual death of wolves due to illegal shooting occurs mainly in the zones of the most highly developed animal husbandry. Thus, wolf populations can tolerate such poaching prey if they are managed correctly, with due regard to timing and other criteria.

\section{LITERATURE}

1. Boreiko V.E. In defense of the wolves. - Kiev: Kiev Ecological and Cultural Center, 2011. -- 156 p. (Wildlife Conservation; issue 68). - ISBN 978-966171-495-2

2. Bibikov D.I. et al. Wolf. - M. - Science. -1985. - 605 p.

3. Kidirbaeva A.Yu. On the issue of managing wolf populations in the Southern Aral Sea region // Materials of the XXIV International Scientific and
Practical Conference "Science in the Modern World". - (Russia, Taganrog). - 2015. -- P.9 - 12.

4. Kidirbaeva A.Yu., Mamabetullaeva S.M. The ecology of the wolf (CanisLupusLinnaeus, 1758) in the modern conditions of the Southern Aral Sea region / Кидирбаева А.Ю., Мамбетуллаева С.М./ Bulletin of the Dagestan State Pedagogical University. - Series Natural and exact sciences. Dagestan. -2009. - No. 2 (7). - P.41-43. file:///E:/ekologiva-volka-canis-lupus-linneus-vsovremennyh-usloviyah-yuzhnogopriaralya\%20(1).pdf.

5. Mambetullaeva S.M., Kidirbaeva A.Yu. Bioecological features of a wolf (CanisLupusLinnaeus, 1758) in the conditions of the Southern Aral region // Scientific medical bulletin. -Tambov (Russia). - 2015. - No. 2 (2). P.76 - 82.5. DOI: 10.17117/nm.2015.02.076/ https://ukonf.com/doc/nm.2015.02.pdf\#page $=76$

6. Kolenoskj G. Wolf predation on wintering deer in east-central Ontario // J. Wildlife Manag. -1972. Vol. 36. - № 2: - p. $358-359$.

7. Mech D.L., Frenzel L. Ecological studies of the timber wolf in Northeastern Minnesota-US Dep. Agr. Forest.Serv. Res.Pap.1971 a NO-52. - 62 